\title{
Public opinion on policy and budgetary trade-offs in European welfare states: evidence from a new comparative survey
}

\author{
Marius R. Busemeyer ${ }^{a}$ and Julian L. Garritzmann ${ }^{a, b}$ \\ a Department of Political Science and Public Administration, University of Konstanz, Konstanz, \\ Germany; ${ }^{b}$ Department of Political Science, University of Zurich, Switzerland
}

\begin{abstract}
In the wake of the 'Great Recession', welfare states have entered a new phase of austerity. Simultaneously, new social risks and the rise of the knowledge economy fuel new demands on the welfare state. We analyse how demands for social investment policies - particularly education - come into conflict with budgetary concerns, using new survey data on individual-level preferences in eight European countries. Paying particular attention to fiscal and budgetary trade-offs, we find that social investments are generally very popular, but as soon as realistic budget constraints are added, public support drops considerably. The largest drop occurs when social investments would be financed with cutbacks in social transfers rather than higher taxes or higher public debt levels. Furthermore, when studying the determinants of preferences, we find that in the era of permanent austerity distributive conflicts within welfare states exhibit a different political dynamic than conflicts about the size of the welfare state.
\end{abstract}

KEYWORDS Education policy; INVEDUC survey; policy trade-offs; public opinion; social investment; welfare state

\section{Introduction}

For some time now, welfare state researchers have observed the expansion of 'social investment policies', such as education policies, active labour market policies, or service-oriented family policies, in a number of European welfare states (Bonoli 2013; Esping-Andersen 2002; Hemerijck 2013; Morel et al. 2011). Social investment policies are believed to be very popular among the general public (Ansell 2010: 136; Busemeyer 2012; Garritzmann 2015), and are often regarded as more effective responses to the new challenges facing welfare states after the emergence of 'new social risks' compared to traditional social transfer policies. At the same time as they are facing these new demands, the fiscal and political leeway of policy-makers 
to respond to these new challenges is increasingly limited owing to budgetary constraints in an era of 'permanent austerity' (Pierson 2001), so that the transformation of existing welfare states towards the 'social investment' model would have to go along with significant cutbacks in existing programmes, increased taxes or higher levels of public debt - all of which can be expected to be unpopular with voters.

Related to shortcomings of available international comparative surveys of public opinion, there is very little research on how citizens perceive and react to these kinds of policy and fiscal trade-offs. Are people willing to increase social investments even if this implies higher taxes, increased public debt or cuts in other welfare state areas? In this contribution, we present new and original data from our own representative survey of public opinion in eight Western European countries. We focus on support for public spending on education because previous research has shown that increasing education spending is hugely popular among voters (Ansell 2010: ch. 4; Busemeyer 2012; Garritzmann 2015), which makes it a good test case for studying the impact of trade-offs on patterns of public opinion.

To briefly foreshadow our main findings, we first confirm the expectation that social investment is highly popular (72 per cent of respondents demand more spending on education), but we also find that support drops significantly (to 27 per cent), when this additional spending would have to be financed by cutbacks in other parts of the welfare state. Even though support decreases strongly in these cases as well, citizens seem more willing to accept tax hikes or higher levels of public debt in exchange for additional education spending.

The second major finding is that the determinants of people's attitudes vary in their explanatory power, depending on whether and which kinds of policy trade-offs are taken into account. More specifically, we find that distributive conflicts over welfare state reform (the 'distribution of the cake') differ fundamentally from the more general conflict about welfare state expansion (the 'size of the cake'). In the former case, self-interest more narrowly defined as membership in specific beneficiary groups (pensioners, families with young children, etc.) becomes even more important.

\section{Literature review and theory}

Welfare state scholars have known for a long time that reforming social policies carries high political risks (Pierson 2001). Pierson's work was highly influential in framing the debate about the link between welfare state reforms, organized interests, and the mass public, but to a certain extent, it implied a rather simplistic understanding of the link between policy-makers and welfare state constituencies. Pierson's original account focused more on organized interest groups and welfare state constituencies mobilizing against cutbacks of 'their' benefits, but his argument has also been applied to the study 
of welfare state attitudes. In line with this idea, an influential strand in the literature finds that support for different social policies largely depends on selfinterest (e.g., Busemeyer et al. 2009; Iversen and Soskice 2001; Lynch and Myrskylä 2009; Rehm 2009; Svallfors 2004), e.g., pensioners are more likely to support generous public pensions and the unemployed would be expected to demand more spending on unemployment insurance. Furthermore, a number of scholars posit that there is a direct link between public opinion on the welfare state and policy output as policy-makers are broadly responsive to public demands (Brooks and Manza 2007; Rehm 2011; Soroka and Wlezien 2010). Because welfare state retrenchment is generally unpopular (Boeri et al. 2001), the expectation in this literature is that welfare states 'persist' (Brooks and Manza 2007), i.e., large-scale cutbacks are unlikely because they are politically risky.

However, scholars have noted particular anomalies in recent years, which are hard to explain within this framework. For instance, scholars have noted a significant degree of retrenchment in welfare state generosity in Organization for Economic Co-operation and Development (OECD) countries (Allan and Scruggs 2004; Korpi and Palme 2003; Starke 2008). But retrenchment is not the 'only game in town' (Van Kersbergen et al. 2014). In fact, some welfare states have significantly expanded their commitment to 'social investment' such as early childhood education, active labour market policies and service-oriented family policies (Bonoli 2013; Hemerijck 2013; Morel et al. 2011; Vandenbroucke and Vleminckx 2011), often at the same time as they were cutting back the more traditional transfer-intensive parts of the welfare state, potentially signalling a qualitative 'recalibration' of welfare states catering to new social risks (Hemerijck 2013: 104). But, of course, it might also be the case that the expansion of the social investment components of welfare states amounts merely to 'sugarcoating' less popular retrenchment, since the former are relatively cheap compared to traditional social insurance policies (Bonoli 2013). These brief examples show that welfare states do not just 'persist' (Brooks and Manza 2007); rather, we observe a complex pattern of retrenchment and systemic (transformative) change, often happening simultaneously. But we do not know whether these shifts are responses to genuine changes in popular demand or whether there is a disconnect between people's attitudes and policy changes in the sense that the latter result from increasingly binding constraints on the part of policy-makers, not citizens' demands.

Existing research has not been able to answer this question in a satisfactory manner. There are only few studies of trade-offs in fiscal or social policy in individual countries and/or policy areas (e.g., Hansen [1998] for the United States and Boeri et al. [2001] for pensions in Western Europe). This is largely because available public opinion surveys contain few questions on social investment policies and, more importantly, they do not take into account important 
constraints and trade-offs between different parts of the welfare state. One of the most widely used surveys in this literature is the International Social Survey Programme (ISSP), which asks whether respondents would prefer more or less public spending on a battery of policy areas. The ISSP question wording mentions that raising public spending 'might require' tax increases, but this is a rather weak formulation of a constrained/trade-off scenario.

A first question is therefore how public support for existing or new social policies would change once budgetary trade-offs are fully acknowledged. On the one hand, the acknowledgement of budgetary trade-offs might have no effect on public support, simply because citizens do not care about budgetary limitations when voicing demands vis-à-vis policy-makers. This is actually the implication of Pierson's (2001) 'new politics' argument, when applied in fully consistent manner. Voters are only (or primarily) interested in maintaining 'their' welfare state programmes; hence their support should not waver once trade-offs are taken into account. On the other hand, citizens could mediate their demands when they become aware of trade-offs. When reminded that additional spending would have to be financed with higher taxes, higher levels of public debt, or cutbacks in other parts of the budget, (some) citizens could become less supportive of these spending increases. Furthermore, if policy feedback effects indeed occur, citizens should be most reluctant to finance additional spending with cutbacks in other parts of the welfare state and more open to financing additional spending with higher taxes or public debt, in case public demand for this spending is sufficiently high.

Therefore, our first hypothesis is:

Hypothesis 1: In general, individual-level support for increasing (education) spending drops once trade-offs between spending and taxation as well as trade-offs between different parts of the welfare state are acknowledged. The drop in support is stronger in the latter case, since these refer to cutbacks in highly visible social policies.

The second hypothesis we want to test in this contribution is more complex and relates to differences in the determinants of spending support, depending on which kinds of constraints are enforced. The bulk of the pertinent literature on welfare state attitudes and redistributive preferences cited above has been concerned with studying the determinants and variation of individual preferences along the dimension of 'more or less' redistribution and/or social spending, identifying variables such as income, educational background, age, gender, religious affinity or individual partisan ideology (see Svallfors [2012] for a recent overview). The core argument we want to develop in the following, however, is that these conflicts about the overall size and generosity of the welfare state play out on a different political level than conflicts about the (re-)distribution of resources across different parts of the welfare state. 
Distributive conflicts within welfare states might be more determined by material self-interest defined in a narrower way as belong to particular welfare state constituencies. Here, we focus on distributive conflicts between the beneficiaries of 'old' and 'new' social policies (Vandenbroucke and Vleminckx 2011), i.e., social transfer programmes such as pensions, on the one hand, and new kinds of social investment policies such as education and family policies, on the other. In general, the trade-off between social investments and passive social transfers is often depicted as one between policies that create diffuse benefits at some point in the future vs social policies that have concrete benefits in the present (Streeck and Mertens 2011). For example, today's investments in education and early childcare will pay off when young generations who enjoy these benefits today enter the labour market at some distant point in the future. In contrast, pension and unemployment schemes entail immediate benefits for those who receive them. Cutting back social transfers to expand social investment is therefore difficult, because the diffuse benefits of social investments in the future are usually not sufficiently strong to outweigh the materialist interests of pensioners and the unemployed. The electoral constituencies and organized interests associated with social investment are also believed to be politically less influential compared to the defenders of the traditional welfare state. This is even more difficult in times of austerity, when budget pressures necessitate reductions in spending (Breunig and Busemeyer 2012; Streeck and Mertens 2011).

This perspective, however, neglects the fact that social investments often produce immediate benefits as well - and often beyond the group of those who are immediately affected. The case of early childhood education is a simple example: the expansion of childcare provision does not only benefit the children themselves (now or in the future), but also increases the opportunities for young parents to combine family life with employment (for many: Van Lancker 2014). Thus, the welfare state constituency group that supports the expansion of childcare opportunities - (young) parents - might easily be at least as large as some defenders of traditional social transfers (e.g., the unemployed or the disabled). Therefore, the trade-off could be less about future-oriented investments vs consumption-oriented social transfers, but simply reflect the emergence of new redistributive conflicts between old and new welfare state constituencies.

Our central hypothesis is that in contrast to the general political conflict about redistribution and the size of the welfare state, material self-interest more narrowly defined (i.e., being beneficiaries or financiers of particular social policies) will play a larger role in redistributive conflicts within the welfare state. The reason is that when it comes to (re-)distribution within the welfare state, services and transfers are very visible and concrete for those who immediately benefit from them, whereas the issue of redistribution and welfare state generosity is located on a more abstract level so that general 
value and ideological orientations as well as the individual's general socioeconomic position with regard to income, education and age matters more.

Hence, the second hypothesis is:

Hypothesis 2: Conflicts about the overall size/generosity of the welfare state play out on a different political dimension than conflicts about the (re-)distribution of resources across social policy sub-fields. In the former case, individuals' ideology, normative orientations and socioeconomic positions are expected to matter more, whereas in the latter case we expect material self-interest more narrowly defined (i.e., being beneficiaries or financiers of particular social policies) to have stronger impacts.

\section{Operationalizing trade-offs at the individual level: introducing a new dataset}

Methodologically speaking, the measurement of trade-offs in individual preferences for welfare state policies is challenging. Existing internationally comparative surveys such as the European Social Survey (ESS) or the International Social Survey Programme (ISSP) contain questions about preferences for public spending, but unfortunately these questions acknowledge neither budgetary constraints nor policy trade-offs. Accordingly, new data is needed. We can rely on original comparative survey data, which for the first time allows measuring attitudes towards budgetary and policy trade-offs at the individual level across European welfare states. This original survey data was collected in the project 'Investing in Education in Europe' (INVEDUC) in eight European countries. The countries are selected as representatives of different welfare state regimes in Western Europe: Germany and France for the corporatist welfare state regime, the United Kingdom (UK) and Ireland for the liberal world, Denmark and Sweden for the social democratic variety, and Italy and Spain as Southern European welfare states.

The target population is each country's adult population (aged 18+) and the sample is representative of each country's population. The survey was conducted by a professional institute (TNS Infratest Sozialforschung) and used computer-assisted telephone interviewing (CATI) (see Busemeyer et al. [2017] for more technical details, as well as a descriptive overview). In the descriptive statistics below, we use a design-weight and a selectivity-weight to correct for selection probabilities. In the multivariate regression analyses, we refrain from applying weights because the independent variables control directly for differences in the dependent variable related to these characteristics and avoid relying on the 'black box' of weighting (DuMouchel and Duncan 1983). The robustness section in the Online Appendix shows that the results remain in line with our expectations, even if we do include survey weights in the analyses.

A pre-test was conducted in all eight countries in February/March 2014. The actual fieldwork took place between mid-April and end of May 2014. 
The net number of interviews differed slightly between countries $(1,000-1,500$ respondents in each country) in order to acknowledge differences in the size of the target populations in the respective countries. Table A1 in the Online Appendix displays the number of interviews per country and the respective response rates. The average response rate was roughly 30 per cent, with a high of 36 per cent in Denmark and a low of 20 per cent in Ireland, which is comparatively high for these kinds of surveys (cf. the discussion in Busemeyer et al. [2017]). The average length of an interview was 25 minutes.

\section{Trade-offs in the welfare state (I): education vs. taxes, debt or pension cuts}

We confronted respondents with two different sets of questions to find out how they perceive and react to policy and budgetary trade-offs in the welfare state. In this first part of the empirical analysis, we use a series of questions that tries to measure individuals' support for social investment given different kinds of constraints. Respondents were randomly assigned to four different groups (one 'control' group and three different 'treatment' frames). ${ }^{1}$ Table A2 in the Online Appendix shows that the random assignment worked in the sense that there are no significant differences in the most relevant variables across the subgroups.

The exact wording was:

Split 1 ('Control'): 'The government should increase spending on education.'

Split 2 ('Treatment 1'): 'The government should increase spending on education, even if that implies higher taxes.'

Split 3 ('Treatment 2'): 'The government should increase spending on education, even if that implies cutting back spending in other areas such as pensions.'

Split 4 ('Treatment 3'): 'The government should increase spending on education, even if that implies a higher public debt.'

Subsequently, respondents were asked whether they would strongly agree (5), agree (4), neither agree nor disagree (3), disagree (2), or strongly disagree

(1) with the statement.

\section{Descriptive findings}

Figure 1 is a simple graphical representation of the means (and 95 per cent confidence intervals) of the control group and the three different treatments. Unpaired t-tests of differences in means between the control and treatment groups reveal that all group means are significantly different (see Table A3 in the Online Appendix). We find, first of all, that education spending is highly popular among the general public: When no constraints are added 


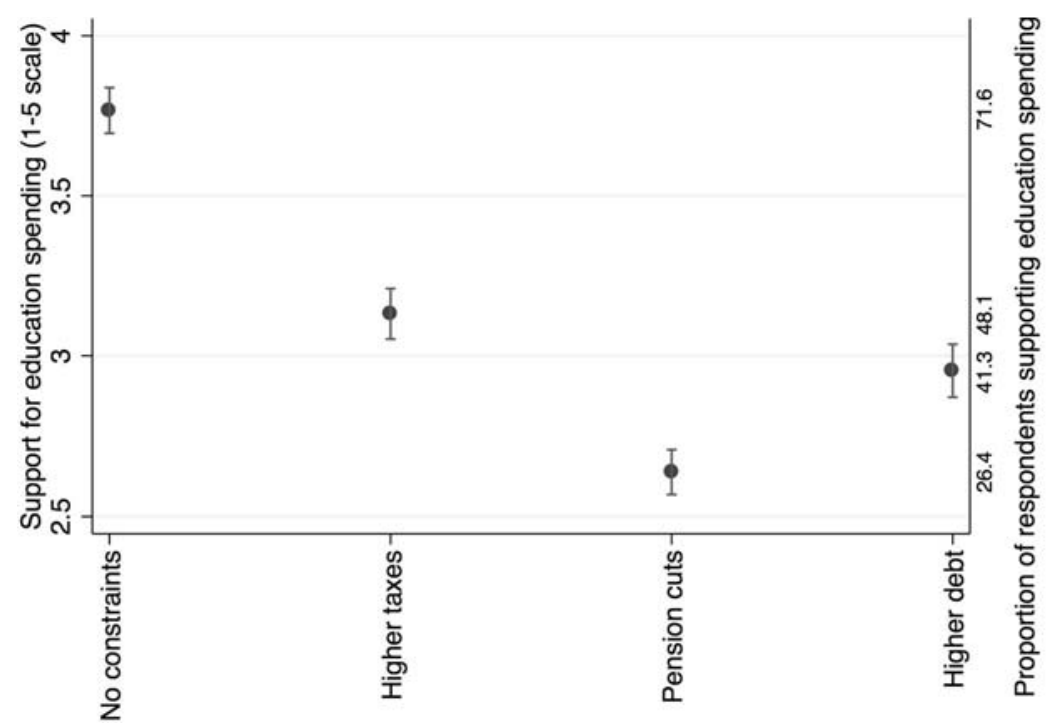

Figure 1. Trade-offs in the welfare state: means and 95 per cent confidence intervals of control and treatment groups.

(i.e., the 'control' group), the mean support for more education spending is 3.77 on the five-point scale. This is equivalent to a share of 71.6 per cent of respondents expressing support for more or much more public education spending. This finding is in line with the existing literature, which also finds a high degree of public support for education spending based on ESS and ISSP data (Ansell 2010: 136; Busemeyer 2012; Garritzmann 2015).

As Figure 1 shows, support drops from 3.77 to 3.13 when respondents are reminded that more education spending might imply higher taxes, which is equivalent to a share of 48.1 per cent supporting (much) more spending. Support for additional education spending decreases even further when this spending would need to be financed with higher levels of public debt (to an average value of 2.95 , which is equivalent to 41.3 per cent of the respondents supporting (much) more spending). It is interesting to see that respondents are actually more supportive of additional taxes than of higher public debt (i.e., a relative majority would be willing to accept higher taxes in exchange for higher public spending on education). This might also at least partly be owing to the time period of our survey during the aftermath of the Great Recession, with omnipresent discourses on extraordinarily high levels of public debt.

The most important finding from Figure 1 is, however, that support for additional education spending is reduced to a low average value of 2.64 when increases in education spending would imply cutbacks in other parts of welfare state, namely pensions. The huge majority supporting education 
spending in the unconstrained scenario (72 per cent) is now reduced to a small minority of 26.4 per cent supporting (much) more education spending. Thus, reducing spending in other parts of the welfare state is much more unpopular than rising taxes or increasing public debt. The magnitude of differences in means between groups is striking, as is the fact that all these differences are highly statistically significant (cf. Table $A 3$ in the Online Appendix). This is a strong confirmation of the power of the reinforcing feedback effects that Pierson $(1993,2001)$ talks about and clearly confirms our first hypothesis.

Figure A1 in the Online Appendix displays the cross-country variation in responses to the trade-off questions. This figure shows that there is some variation across country contexts, but apart from a few outliers (France and Italy in some of the treatment groups), the cross-national variation is much smaller than the differences between group averages.

\section{Determinants of individual preferences}

In the following multivariate regression analyses we identify individual-level characteristics that correlate with people's support/opposition to education spending, depending on which trade-off scenario is presented. To reiterate our hypothesis, we expect that material self-interest more narrowly defined as membership in particular welfare state beneficiary groups has more explanatory power than broader societal cleavages once the conflict is about (re-)distribution within the welfare state rather than its overall size. Several additional analyses and detailed robustness tests can be found in the Online Appendix.

Building on the insights of the large literature on welfare state attitudes cited above, the models contain variables related to self-interest as well as ideological and normative orientations. More specifically, the following independent variables are included. EDUCATIONAL BACKGROUND measures the individual's educational experiences on a five-point scale from basic education to university-level education. Previous research has shown that highly educated individuals are also more likely to support the further expansion of educational opportunities (Ansell 2010; Garritzmann 2015), even though this might seem counterintuitive from a narrow rational-choice perspective (Busemeyer 2012: 230). Individual (net) INCOME is given in purchasing-power adjusted United States (US) Dollars, recategorized in countryspecific income quintiles. Expectations on the association between income and support for education spending are somewhat ambivalent, however, because the redistributive consequences of educational investments are more complex than those of other social policies (Ansell 2010; Busemeyer 2012; Garritzmann 2016). Hence, we do not expect a strong association between respondents' income and their education policy preference in this case. Expectations related to demographic variables are more straightforward: RETIRED persons should be less supportive of more education spending 
because they are not likely to benefit themselves anymore, whereas STUDENTS AND PUPILS, WOMEN and respondents with SMALL KIDS AT HOME should exhibit higher levels of support.

In addition to variables related to demographics and socioeconomic positions, we include variables measuring ideological orientations, operationalized as LEFT-RIGHT ORIENTATION, based on individuals' self-placement on an 11-point-scale from 0 (left) to 10 (right). Finally, respondents' preferences towards PUBLIC SPENDING IN GENERAL could be taken as an indicator of predispositions towards the role of the state. This variable measures individual responses to this question:

A share of the national government's annual budget is spent on social benefits and social services. Please tell me, according to you: Should the government spend much more, more, the same, spend less or much less on social benefits and social services?

Again, responses are recorded on a five-point Likert scale with higher values indicating stronger support for state involvement. Obviously these two attitudinal variables are at least partly endogenous, i.e., individuals' social policy preferences also contribute to shaping their partisan worldviews and normative predispositions towards the state. However, the problem of endogeneity could be less severe in our setup, because we study policy trade-offs rather than simple social policy preferences. Ideology and normative orientations are factors that are part of deep belief systems and thus likely to affects individuals' perceptions of trade-offs. Particular responses to trade-offs, however, would not necessarily determine ideological predispositions. That said, we still interpret the findings with caution and understand them rather as correlational associations than as strong causal statements.

Regarding methods, simple techniques are sufficient for the purpose of this contribution. We dichotomize the dependent variables in order to facilitate interpretation of the coefficient estimates because we are mainly interested in the determinants of people's support for welfare state reform. In all four subgroups, therefore, support for (much) more spending is coded as ' 1 ', whereas support for the same or less spending is coded as ' 0 '. In the main analyses, we report results from logit models (the results are also robust to other model specifications such as probit or ordered logit). The structure of the dataset is hierarchical (individuals nested within countries), but the number of level-2 units (eight countries) is not sufficient to run multi-level models including macro-level variables. We therefore include country dummies as a best-practice solution to account for potential contextual effects and cluster the standard errors by countries. In additional robustness tests (reported in the Online Appendix), we ran regressions for each individual country to find out whether the determinants vary across contexts. The intuition is that if we are able to show that the effects of the micro-level factors are 
similar across countries, we can carefully conclude that while contexts certainly matter, they leave the results reported here unaffected. Our results indeed support this reasoning, which is why we only report results for the pooled sample in the main analysis.

To make the findings more accessible, average marginal effects are plotted in Figure 2 (the full regression tables are included in Table A4 in the Online Appendix). Taken together, a clear pattern emerges from the regression analyses. First of all, there is a distinction between questions about the overall level of public education spending and its financing via higher taxes or public debt on the one hand (models 1,2 and 4) and the question of redistributing resources from other parts of the welfare state (pensions) to education on the other (model 3). In the first set of questions (education versus taxes or debt), educational background, left-right orientation and general spending preferences are associated with support for education spending: highly educated, left-leaning, and pro-state individuals are more likely to support education spending, whereas individuals with little education, a rightist ideological orientation and a greater scepticism regarding the role of the state tend to be more opposed. These findings are thus in line with previous findings on the determinants of people's welfare state attitudes. As expected, individual income does not matter much, nor does being female or retired.

In the question about redistributing resources within the welfare state, however, these variables lose explanatory power (model 3): neither respondents'

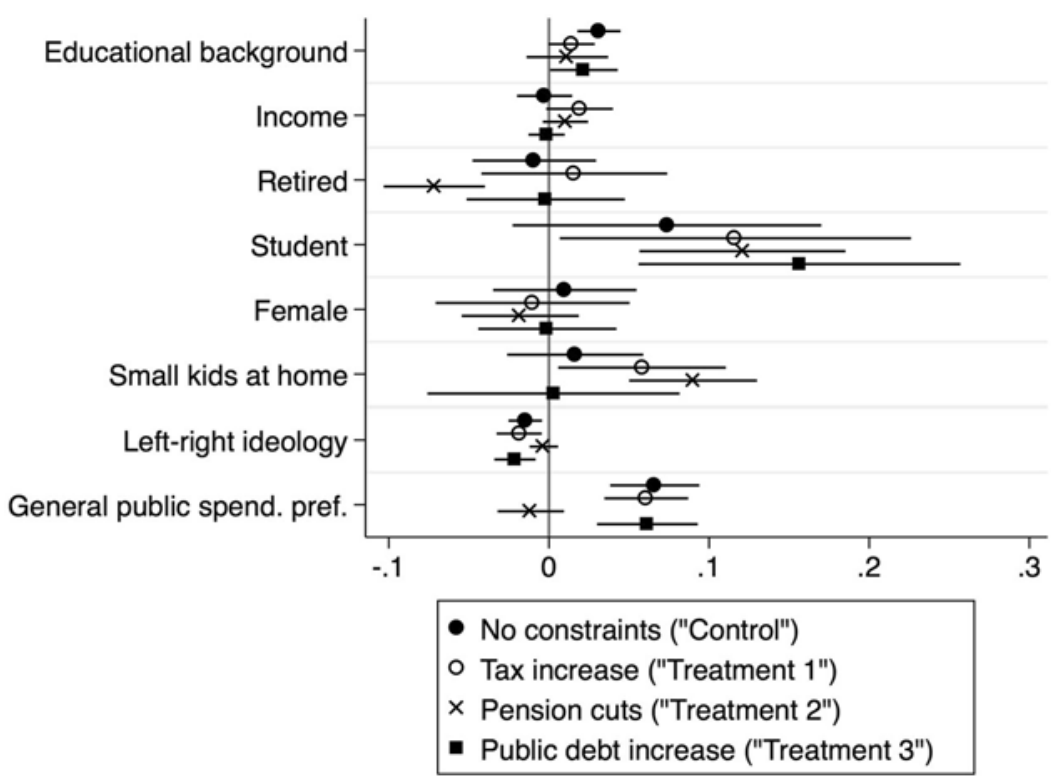

Figure 2. Average marginal effect plot of determinants of support for education spending across different models. 95 per cent confidence bands. 
educational background, income, or left-right position, nor general spending preferences are significantly associated with spending support. Instead, variables related to individuals' membership in (partly latent) welfare state beneficiary groups turns out to be significant: the retired are - for obvious reasons strongly opposed to taking away resources from pensions to increase spending on education. Using model 3 , the predicted change in the probability for a retired person to support education spending compared to a non-retired person is a reduction of about 6 percentage points. ${ }^{3}$ Vice versa, individuals with small kids at home are more likely to support taking away resources from pensioners to fund educational investments. Simulating a similar change as above yields an increase in support for education spending for individuals with children at home of about 10 percentage points. Being in education (student, vocational training or in school) is also associated with a higher support for education spending. Similar to the other variables capturing beneficiary groups, the average marginal effect of being in education becomes larger once trade-offs and constraints are acknowledged. Compared to the variable indicating the presence of small kids at home, however, the effect is strongest in the case of trade-offs between spending and higher levels of public debt, i.e., young persons in education are more likely to support education spending even if that entails higher levels of public debt. At first sight, this seems counterintuitive, but a plausible explanation could be that young individuals have a shorter time horizon and are therefore less concerned about increasing levels of public debt. In general, confidence intervals for this group of individuals are larger because they represent a relatively small share of the sample.

\section{Trade-offs in the welfare state (II): compensatory spending vs social investment}

In order to gain deeper insights into people's preferences on policy trade-offs, we confronted respondents with a second set of questions. Here, respondents had to choose between social investments and passive social transfers. We split the total sample into two groups, and assigned individuals randomly to either group. The first question aims at measuring support for social investment at the expense of compensatory spending:

What do you think about the following statement? To be able to finance more spending on education and families, the government should cut back on old age pensions and unemployment benefits.

In contrast, the second question captures support for the passive welfare state at the expense of social investment:

What do you think about the following statement? To be able to finance more spending on old age pensions and unemployment benefits, the government should cut back spending on education and families. 
Again, respondents' answers were coded on a five-point Likert scale (strongly agree, agree, neither agree nor disagree, disagree, strongly disagree). For the multivariate regression analyses, this variable is again dichotomized, taking the value ' 1 ' for individuals who (strongly) agree and ' 0 ' for the remaining cases. This is a rather conservative measure of support for the respective policy reforms, because there are fewer cases in these categories compared to the general spending question used above.

\section{Descriptive findings}

When looking at the descriptive statistics (Table A5 in the Online Appendix), one conspicuous finding is that for both social investment and compensatory spending, support for additional spending declines precipitously once respondents are confronted with trade-offs. In the unconstrained question on support for education spending discussed above, about 72 per cent of all respondents expressed support for (much) more education spending. In contrast, only 11.26 per cent demand (much) more spending on 'education and families' if this additional spending would be financed with cutbacks in passive social transfers. Even fewer (7.82 per cent) would like to see (much) more spending on old age pensions and unemployment benefits if this is to be financed by cutbacks in education spending. The largest share of respondents disagrees with both statements, a very sizable minority even strongly. In other words: Citizens strongly dislike being confronted with policy trade-offs, i.e., being forced to choose between different policies. The overall message from the findings is clear and confirms the previous section: public support for spending increases drops precipitously once respondents are confronted with a clear trade-off problem between different social policies, independent of whether they are asked about social investments or passive social transfers.

\section{Determinants of people's preferences}

Next, we present findings from multivariate regression analyses on the determinants of support for social investment and passive social transfers respectively. We also include a third dependent variable that captures general preferences for redistribution. Support for redistribution is measured by respondents' degree of agreement with the statement: 'The government should reduce income differences between the rich and the poor.' This is done in order to achieve a similar comparison as above between a relatively unconstrained setting on the one hand and a more constrained situation, where respondents are confronted with trade-offs, on the other hand. This way it is possible to see whether conflict lines about social investments and social transfers are similar to classical redistributive conflicts. As above, we 
employ single-level logit models with standard errors clustered by country and including country dummies, and we use the same set of independent variables. We also looked at country-specific regressions, which did not reveal any systematic patterns, so we focus on the pooled sample here (see robustness section in the Online Appendix). Again, results are presented in the form of plotted average marginal effects (Figure 3). A regression table can be found in Table A6 in the Online Appendix.

In general, the findings of this second empirical test point in the same direction as the ones from the first analysis. First, supporting coalitions for social investments differ from those of passive social transfers in important ways. Increasing spending on social investments, even if it entails cutting back pensions and unemployment benefits, is strongly supported by individuals with small children at home and by students. The predicted change in the probability of supporting social investment is an increase of about 5 percentage points in both cases. In contrast, pensioners are more likely to oppose social investments if they would be financed with cutbacks in pension spending. Here, the predicted change in probability is a decrease of similar magnitude (4 percentage points). When it comes to passive social transfers, however, individuals with small kids at home are more likely to oppose spending (the predicted change in probability is 3 percentage points). We also find that highly educated individuals are more opposed to spending on passive

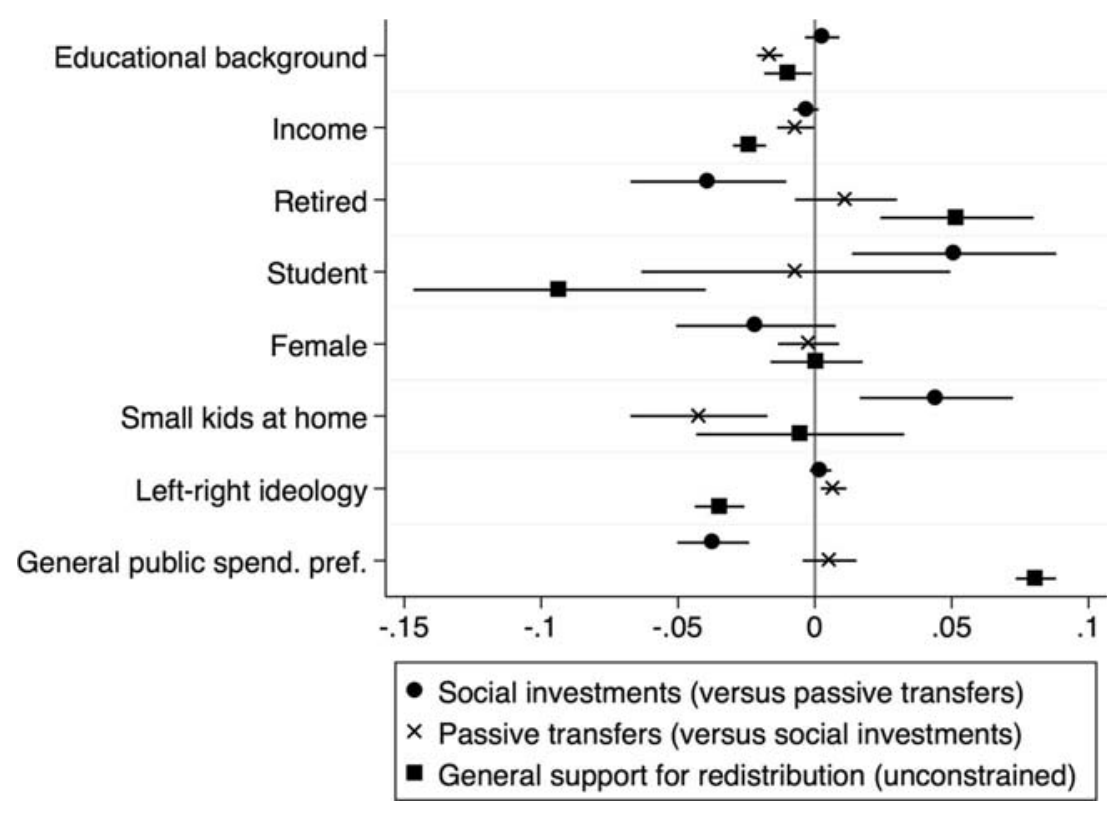

Figure 3. Average marginal effect plot of determinants of support for social investment spending, passive transfers and redistribution. 95 per cent confidence bands. 
social transfers. The magnitude of the effect is comparable to that of the 'small kids' dummy.

Second, and most importantly for the purposes of this contribution, there are important similarities across the two policy types, even though the underlying supporting coalitions are different. The similarities concern the fact that in both cases, self-interest more narrowly defined as belonging to particular welfare state constituency groups rather than broader socioeconomic cleavages determines preferences. These results can be regarded as strong confirmation of Hypothesis 2. With some exceptions, the general pattern is that variables related to broad societal cleavages are more powerful in accounting for variation in general support for redistribution. In contrast, when respondents are forced to make choices between social investments and passive transfers, variables related to self-interest more narrowly defined such as having small children at home, being in education or retired, become more important. In other words, we find that attitudes on redistributing fiscal resources within the welfare state, i.e., from one policy to another, are less affected by whether respondents are rich or poor, male or female, left-- or right-wing-oriented. Instead, what matters is to which (latent) welfare constituency individuals belongs, i.e., whether one has children, is retired, in education, or whether one does not belong to any of these groups. What is also interesting is that general support for social spending is positively associated with support for redistribution (as one would expected), but negatively associated with support for social investments. This might indicate that people think more about traditional social policies than about social investment when asked about their general preferences towards public spending. In the Online Appendix, we report a number of robustness tests, none of which revealed worrisome results.

\section{Conclusions}

This contribution added a new perspective to the ongoing debate about welfare state reform by focusing on public opinion towards policy and budgetary trade-offs. Instead of summarizing the findings again, we focus on their implications in this concluding section. First of all, for scholars interested in public opinion, our findings raise some questions with regard to the reliability of existing surveys. Many surveys (such as the ISSP) do not take into account constraints and therefore might significantly overestimate people's 'true' support for spending. We thus need to devise new survey items in particular for comparative questions that take the complexity and multidimensionality of preferences more seriously. We regard our survey and our analysis as an important complement to the existing data and research rather than a substitute, but believe that more needs to be done to devise good measures of public attitudes towards trade-offs. 
Future work could strongly enrich the literature by using novel techniques such as conjoint analyses, which is a promising alternative way to model trade-offs scenarios.

Second, our findings have implications for the world of policy-making. The political viability of the 'social investment state' as the newly emerging paradigm in social policy-making could be hampered by the political opposition of powerful constituency groups, if expanding social investments would go along with cutbacks in other parts of the welfare state. Given the limited fiscal room of manoeuvre of most European governments, this seems unavoidable for the most part, however, since increasing taxes or levels of public debt is (often assumed to be) no longer feasible. In a way, therefore, welfare states are - again - caught between a rock and a hard place, because the adoption of existing welfare states to meet new demands will most likely go along with political conflicts about the cutting back of existing schemes. The challenge for policy-makers will therefore be to find viable coalitions (potentially along new cleavages) to cater both to the existing demands from well-established welfare beneficiary groups as well as to the demands of new, often vocal but more heterogeneous groups particularly affected by the emergence of new social risks (cf. also Häusermann 2012). Our findings identified some of the conflict lines, which could be overcome by smart policy design and package deals. Future work should try to develop a better understanding of how these demands are picked up by political actors, particularly political parties, and transformed into policies.

\section{Notes}

1. These are not treatments in a strict experimental sense, because the 'treatment' is measured together with the dependent variable (support for education spending). Yet, it might help readers to think about the questions in these terms.

2. As an alternative proceeding, we also pooled the answers to the four split sample questions into a single variable and included dummy variables for each of the three treatments as independent variables. This procedure yields essentially similar results. Since we are interested in exploring differences in the determinants of preferences across groups, we prefer the current specification. The alternative procedure would require calculating interaction effects of the 'treatment' dummies with all independent variables in the model and would therefore be cumbersome to handle.

3. Gender is set to male and the small kids dummy variable is set to ' 0 '. All other variables are at their mean.

\section{Acknowledgements}

We gratefully acknowledge helpful comments by the special issue editors (Christian Breunig, Christine Lipsmeyer, and Guy Whitten) and by the journal's three anonymous 
reviewers. Previous versions were presented at a workshop on the special issue at Texas A\&M, at the CES Annual Conference in Paris, at the Amsterdam Centre for Inequality Studies, and at the University of Konstanz. We wish to thank the participants at these occasions for critical questions and helpful feedback.

\section{Disclosure statement}

No potential conflict of interest was reported by the authors.

\section{Funding}

We gratefully acknowledge funding from an European Research Council Starting Grant, [grant number 311769].

\section{Notes on contributors}

Marius R. Busemeyer is professor of political science at the University of Konstanz, Germany.

Julian L. Garritzmann is senior researcher at the University of Konstanz, Germany, and at the University of Zurich, Switzerland.

\section{References}

Allan, J.P. and Scruggs, L. (2004) 'Political partisanship and welfare state reform in advanced industrial societies', American Journal of Political Science 48: 496-512.

Ansell, B.W. (2010) From the Ballot to the Blackboard: The Redistributive Political Economy of Education, Cambridge: Cambridge University Press.

Boeri, T., Börsch-Supan, A., Tabellini, G., Moene, K.O. and Lockwood, B. (2001) 'Would you like to shrink the welfare state? a survey of European citizens', Economic Policy 16(32): 8-50.

Bonoli, G. (2013) The Origins of Active Social Policy: Labour Market and Childcare Policies in a Comparative Perspective, Oxford, New York: Oxford University Press.

Breunig, C. and Busemeyer, M.R. (2012) 'Fiscal austerity and the trade-off between public investment and social spending', Journal of European Public Policy 19(6): 921-38.

Brooks, C. and Manza, J. (2007) Why Welfare States Persist: The Importance of Public Opinion in Democracies, Chicago: University of Chicago.

Busemeyer, M.R. (2012) 'Inequality and the political economy of education: an analysis of individual preferences in OECD countries', Journal of European Social Policy 22(3): 219-40.

Busemeyer, M.R., Goerres, A. and Weschle, S. (2009) 'Attitudes towards redistributive spending in an era of demographic ageing: the rival pressures from age and income in 14 OECD countries', Journal of European Social Policy 19(3): 195-212.

Busemeyer, M.R., Garritzmann, J.L., Neimanns, R. and Nezi, R. (2017) 'Investing in education in Europe: evidence from a new survey of public opinion', Journal of European Social Policy, forthcoming. 
DuMouchel, W.H. and Duncan, G.J. (1983) 'Using sample survey weights in multiple regression analyses of stratified samples', Journal of the American Statistical Association 78: 535-43.

Esping-Andersen, G. (2002) Why We Need a New Welfare State, Oxford: Oxford University Press.

Garritzmann, J.L. (2015) 'Attitudes towards student support: how positive feedbackeffects prevent change in the four worlds of student finance', Journal of European Social Policy 25(2): 139-58.

Garritzmann, J.L. (2016) The Political Economy of Higher Education Finance. The Politics of Tuition Fees and Subsidies in OECD countries, 1945-2015, Basingstoke: Palgrave Macmillan.

Hansen, J.M. (1998) 'Individuals, institutions, and public preferences over public finances', American Political Science Review 92(3): 513-31.

Häusermann, S. (2012) 'The politics of old and new social policies', in G. Bonoli and David Natali (eds.), The Politics of the New Welfare State, Oxford: Oxford University Press, pp. 111-34.

Hemerijck, A. (2013) Changing Welfare States, Oxford, New York: Oxford University Press.

Iversen, T. and Soskice, D. (2001) 'An asset theory of social policy preferences', American Political Science Review 95(4): 875-93.

Korpi, W. and Palme, J. (2003) 'New politics and class politics in the context of austerity and globalization: welfare state regress in 18 countries, 1975-95', American Political Science Review 97(3): 425-46.

Lynch, J. and Myrskylä, M. (2009) 'Always the third rail? Pension income and policy preferences in European democracies', Comparative Political Studies 42(8): 1068-97.

Morel, N., Palier, B. and Palme, J. (eds) (2011) Towards a Social Investment State? Ideas, Policies and Challenges, Bristol: Policy Press.

Pierson, P. (1993) 'When effect becomes cause: policy feedback and political change', World Politics 45(4): 595-628.

Pierson, P. (2001) 'Coping with permanent austerity: welfare state restructuring in affluent democracies', in P. Pierson (ed.), The New Politics of the Welfare State, Oxford: Oxford University Press, pp. 410-56.

Rehm, P. (2009) 'Risk and redistribution: an individual-level analysis', Comparative Political Studies 42(7): 855-81.

Rehm, P. (2011) 'Social policy by popular demand', World Politics 63(2): 271-99.

Soroka, S. and Wlezien, C. (2010) Degrees of Democracy. Politics, Public Opinion, and Policy, Cambridge: Cambridge University Press.

Starke, P. (2008) Radical Welfare State Retrenchment. A Comparative Analysis, Basingstoke: Palgrave Macmillan.

Streeck, W. and Mertens, D. (2011) 'Fiscal austerity and public investment: is the possible the enemy of the necessary?', MPIfG Discussion Paper 11/12.

Svallfors, S. (2004) 'Class, attitudes and the welfare state: Sweden in comparative perspective', Social Policy \& Administration 38(2): 119-38.

Svallfors, S. (2012) 'Welfare states and welfare attitudes', in S. Svallfors (ed.), Contested Welfare States: Welfare Attitudes in Europe and Beyond, Stanford: Stanford University Press, pp. 1-24.

Vandenbroucke, F. and Vleminckx, K. (2011) 'Disappointing poverty trends: is the social investment state to blame?' Journal of European Social Policy 21(5): 450-71. 
Van Kersbergen, K., Vis, B. and Hemerijck, A. (2014) 'The great recession and welfare state reform: is retrenchment really the only game left in town?' Social Policy \& Administration 48(7): 883-904.

Van Lancker, W. (2014) To Whose Benefit? An Empirical and Comparative Investigation into the (Un)Intended Consequences of Family Policy in the Social Investment State, Brussels: University Press Antwerp. 